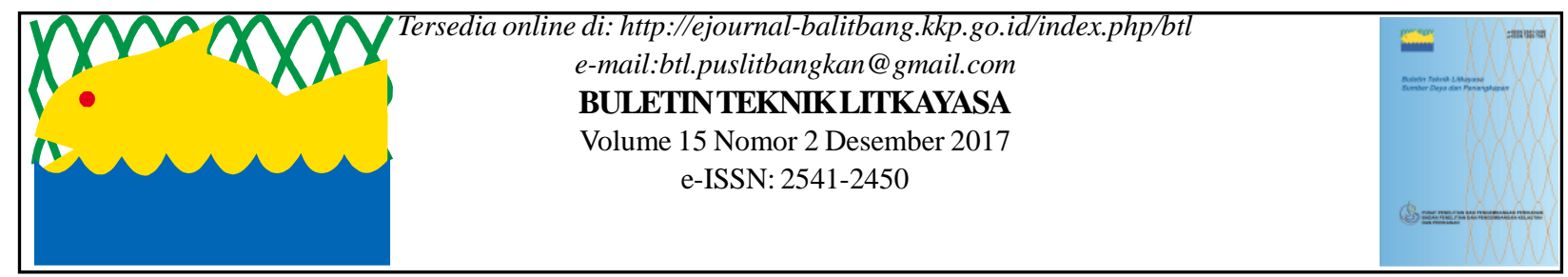

\title{
PENGOPERASIAN PANCING RENGGE (VERTICAL LONGLINE) UNTUK PENANGKAPAN IKAN CAKALANG DI LAUT SULAWESI
}

\author{
Enjah Rahmat dan Adi Surahman \\ Teknisi Balai Riset Perikanan Laut, Cibinong Bogor \\ Teregistrasi I tanggal: 30 November 2017; Diterima setelah perbaikan tanggal: 08 Desember 2017;
}

Disetujui terbit tanggal: 13 Desember 2017

\section{PENDAHULUAN}

Ikan cakalang merupakan salah satu jenis ikan dominan di Laut Sulawesi. Usaha penangkapan ikan cakalang di perairan ini menggunakan berbagai alat tangkap diantaranya pukat cincin, huhate, jaring insang hanyut, dan pancing (pancing ulur, rawai, dan tonda). Tempat pendaratan ikan hasil tangkapan diantaranya terdapat di Manado, Bitung, Kwandang, Toli-toli, Tahuna (Sulawesi) dan Tarakan (Kalimantan).

Dalam rangka kegiatan "Penelitian Karakteristik Biologi Perikanan, Habitat Sumber Daya dan Potensi Produksi Sumber Daya Perikanan Di Laut Sulawesi (WPP 716 )" telah diperoleh informasi mengenai aspek penangkapan dan operasional penangkapan ikan pelagis dengan alat tangkap pancing yang dilakukan oleh nelayan Mandar (Sulawesi Barat) yang beroperasi di Laut Sulawesi serta mendaratkan hasil tangkapannya di PPI Tandoleo Kabupaten Toli-toli (Sulawesi Tengah). Makalah ini menyajikan aspek operasional dan teknik pengoperasian 'pancing rengge' yaitu pancing rawai yang dioperasikan secara vertikal (vertical longline) di Laut Sulawesi

\section{POKOK BAHASAN \\ Lokasi dan Waktu}

\section{Daerah Penangkapan}

Penelitian dilakukan di Toli-Toli (Sulawesi Tengah) pada September 2017. Pengoperasian pancing rengge dilakukan di sekitar rumpon, di daerah penangkapan ikan di Laut Sulawesi pada Area 322 dan Area 323 (Gambar 1). Perjalanan ke daerah penangkapan kirakira selama 13-14 jam dari PPI Tandoleo Toli-toli.

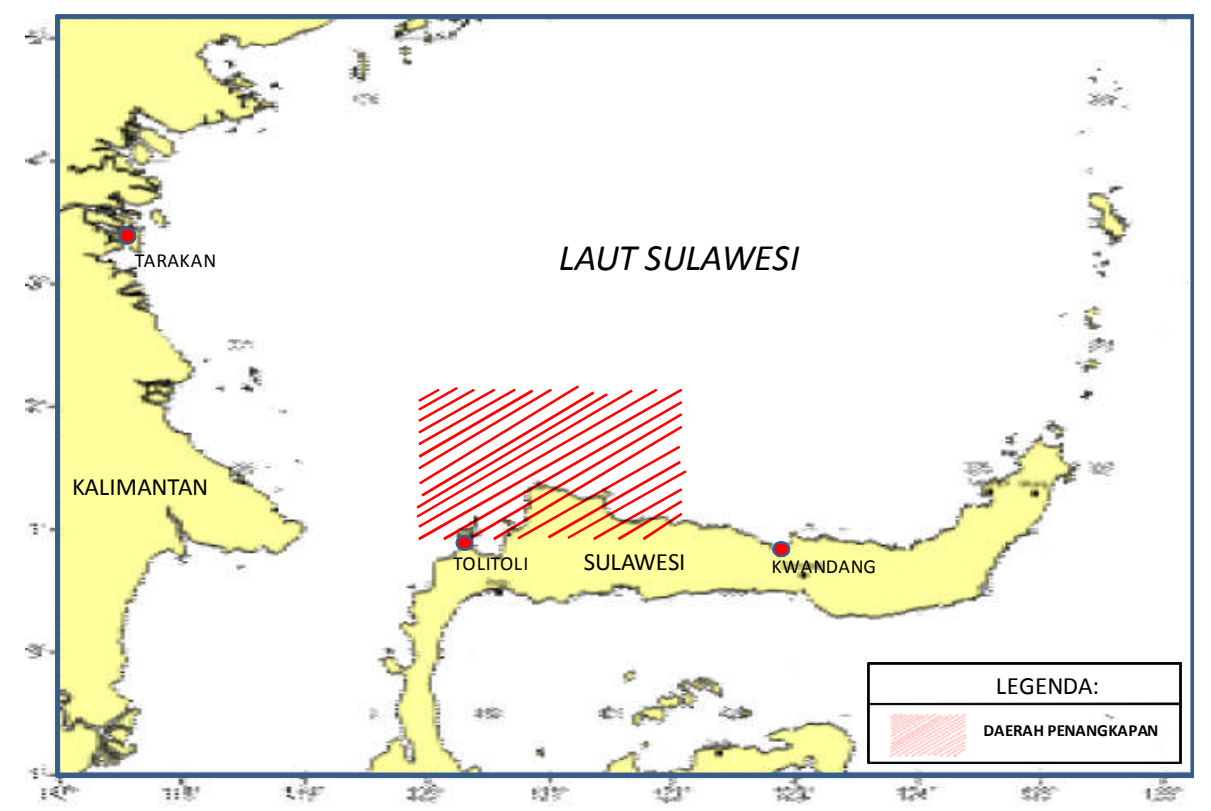

Gambar 1. Daerah penangkapan ikan dengan alat tangkap pancing, September 2017. 


\section{Metode}

Materi bersumber dari hasil wawancara dengan nakhoda dan nelayan pancing nelayan Mandar (nelayan andon) di Toli-toli pada bulan September 2017.

\section{Alat dan Bahan}

Alat-alat dan bahan yang digunakan terdiri dari alat ukur panjang (meteran), alat ukur berat (timbangan), kamera, buku identifikasi ikan. Buku identifikasi ikan mengacu pada Carpenter dan Niem (1998) serta Anonim (2000).

\section{Hasil}

\section{Armada dan Spesifikasi Kapal}

Seperti halnya di Kwandang, di Toli-toli juga ada nelayan andon yang berasal dari Kabupaten Polewali Mandar (Polman), Sulawesi Barat. Kapal pancing nelayan Polman dikenal dengan nama Kapal Mandar dengan ciri khas kapalnya berwarna putih yang dikenal juga dengan sebutan 'kapal penongkol'. Kapal penongkol yang beroperasi di sekitar perairan Tolitoli pada saat ini ada sekitar 14 unit kapal. Setiap unit Kapal penongkol (Gambar 2) terdiri dari Kapal induk dan kapal/perahu tangkap. Kapal induk berfungsi untuk mobilitas pada saat mencari daerah penangkapan (fishing ground) dan menampung ikan hasil tangkapan, kecuali pada saat angin kencang operasi penangkapan ikan dilakukan diatas kapal induk, Kapal tangkap adalah perahu kecil yang disebut 'lepa-lepa'. Jumlah lepa-lepa yang dibawa biasanya sebanyak jumlah ABK yang turut serta dalam trip penangkapan tersebut.

Hasil observasi terhadap kapal contoh KM. Harapan menunjukkan Spesifikasi kapal induk sebagai berikut, kapal mempunyai ukuran panjang, lebar dan dalam (PxLxD) 21,00 x 2,50 x 1,40 meter dan berbobot $4 \mathrm{GT}$. Mesin penggerak menggunakan dua unit mesin yaitu Ratna 295 PK dan satu unit mesin Jiandong 300 PK. Palkah tempat menyimpan ikan hasil tangkapan terbuat dari bahan triplek, dengan ukuran panjang, lebar dan dalam (PxLxD) 2,0 x 1,1 x 1,0 meter. Pada kapal induk biasanya tersedia 2 buah palkah yang dapat menampung ikan sebanyak 3 ton ikan. Pada saat berangkat ke laut kedua palkah tersebut diisi dengan es balok, yang akan digunakan untuk menjaga mutu ikan hasil tangkapan.

Lepa-lepa pada umumnya berukuran panjang, lebar dan dalam (PxLxD) 4,00 x 0,50 x 0,35 meter. Lepa-lepa dioperasikan oleh seorang nelayan/ABK dengan cara mendayung (tidak menggunakan mesin motor). Jumlah hari operasi selama 5 hari per trip.
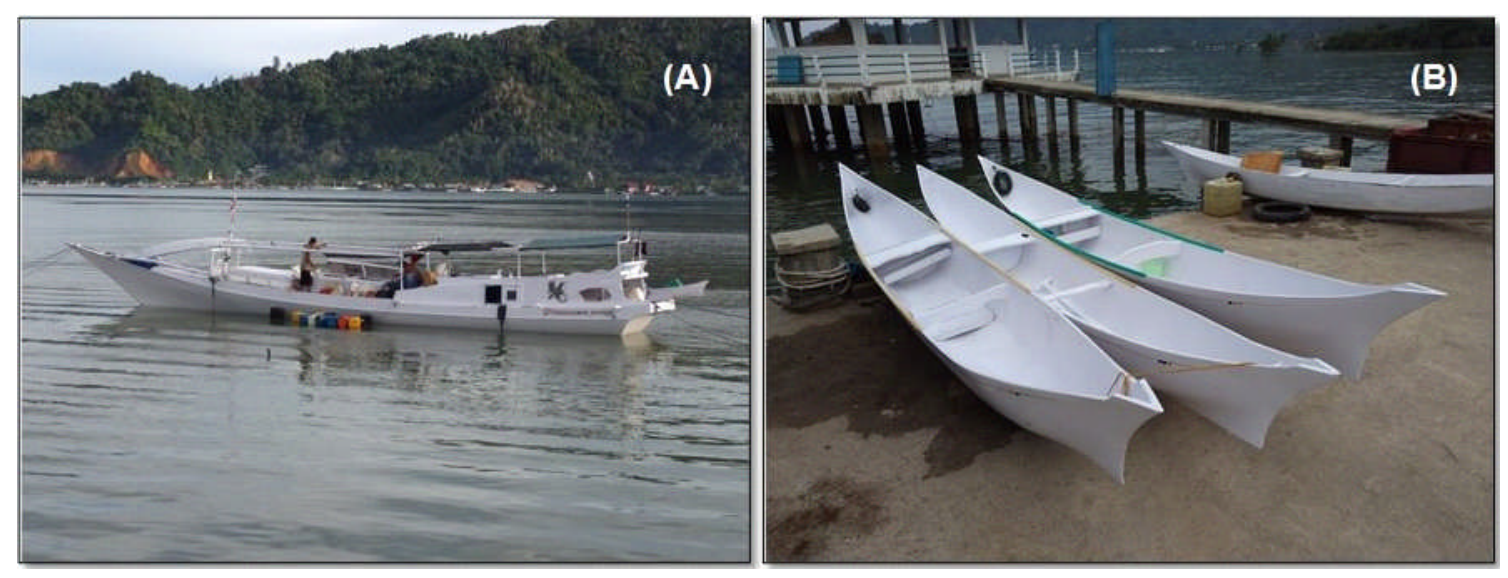

Gambar 2. Kapal motor alat tangkap pancing nelayan Mandar: kapal induk (A) dan lepa-lepa (B).

\section{Alat Tangkap Pancing Rengge}

Nelayan Mandar diketahui mengoperasikan beberapa jenis pancing. Alat tangkap pancing untuk penangkapan ikan cakalang diantaranya pancing rengge, pancing tasi-tasi, pancing pelaru-laru dan pancing bose-bose. Sedangkang untuk menangkap ikan tuna ukuran besar/tuna ekspor digunakan pancing ulur yang disebut pancing kayen.

Pancing rengge adalah jenis pancing rawai yang dioperasikan secara vertikal (vertical longline).
Pancing rengge terdiri dari tali utama, tali cabang, mata pancing, umpan tiruan, pemberat dan kelosan (Gambar 3). Tali utama dan tali cabang menggunakan nylon monofilament sedangkan mata pancing menggunakan jenis mata pancing berkait balik. Dalam 1 unit pancing rengge ada 70-100 mata pancing yang dipasang pada setiap tali cabang. Setiap nelayan membawa 1-2 unit pancing rengge untuk setiap kali melaut. 


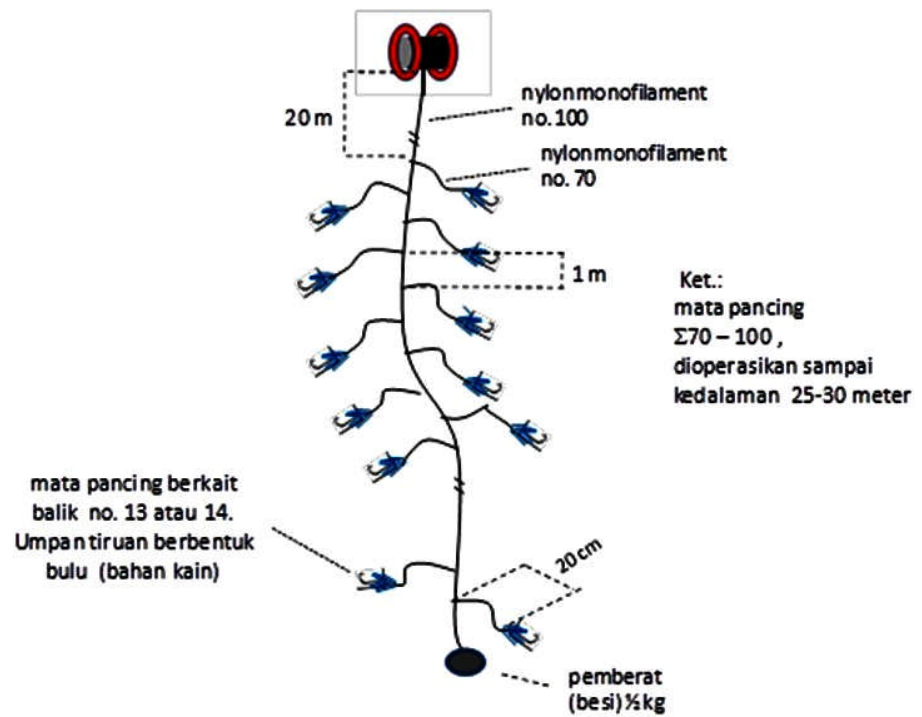

Gambar 3. Konstruksi pancing rengge.

\section{Pengoperasian Pancing Rengge}

Pancing rengge dioperasikan diatas perahu (lepalepa) oleh seorang nelayan/ABK. waktu pengoperasiannya pada waktu subuh (pagi hari) dan pada saat waktu magrib (sore hari). Pada saat mengoperasikan pancing, perahu berjalan perlahan sambil menghela tali pancing. Pancing rengge dioperasikan selama kurang lebih 20 menit untuk setiap kali seting dan dioperasikan di kedalaman 2530 meter dibawah permukaan laut. Pada pagi hari pancing rengge dioperasikan 3-5 kali, demikian juga pada sore hari sebanyak 3-5 kali setting. Target penangkapan pancing rengge adalah jenis ikan cakalang. Pada umumnya setiap kali seting ikan yang berhasil ditangkap berkisar antara 10-50 ekor.

\section{Hasil Tangkapan}

Menurut informasi nelayan pada bulan September 2017 ini baru mulai operasi penangkapan ikan pelagis besar terutama ikan cakalang setelah beberapa bulan sebelumnya tidak musim. Total hasil tangkapan lima jenis alat tangkap pancing kapal penongkol pada salah satu trip penangkapan di bulan September (kapal contoh) masih sedikit sebesar 447 $\mathrm{kg}$, Dari total hasil tangkapan tersebut $27 \%(120 \mathrm{~kg})$ diantaranya adalah hasil tangkapan pancing rengge. Hasil tangkapan pancing rengge (Gambar 4) didominasi oleh jenis ikan cakalang (Katsuwonus pelamis) sebesar $69 \%$, jenis ikan lainnya terdiri dari ikan tenggiri (Scomberomorus sp.) 16\%, tongkol (Auxis sp.) 9\% dan jenis ikan tuna (Thunnus sp.) $6 \%$.

Pada saat pengoperasian alat tangkap masih berlangsung, jenis ikan yang tertangkap sementara disimpan di atas lepa-lepa. Ikan hasil tangkapan selanjutnya dipindahkan dan disimpan di dalam palkah ikan yang terdapat di kapal induk dan untuk menjaga mutu ikan, ikan yang disimpan di dalam palkah diberi es curah.

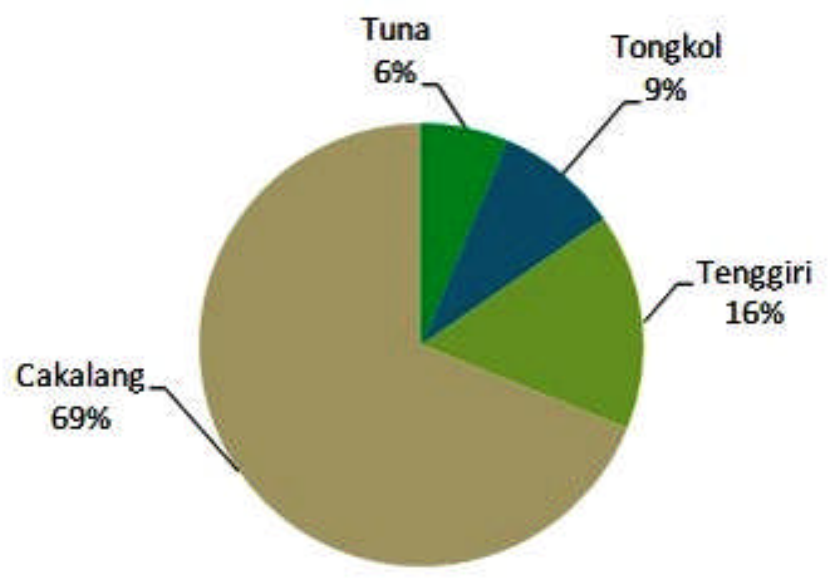

Gambar 4. Komposisi jenis ikan hasil tangkapan pancing rengge, September 2017. 


\section{KESIMPULAN}

Pancing rengge adalah jenis pancing rawai vertikal. dioperasikan pagi dan sore hari di kedalaman 25-30 meter. Pancing rengge dioperasikan dengan lepa-lepa dengan cara dihela. Target penangkapan pancing rengge adalah ikan cakalang.

\section{PERSANTUNAN}

Tulisan ini merupakan bagian dari hasil kegiatan "Penelitian Karakteristik Biologi Perikanan, Habitat Sumber Daya dan Potensi Produksi Sumber Daya Perikanan Di Laut Sulawesi (WPP 716)" oleh Balai Riset Perikanan Laut Cibinong, T.A. 2017. Penanggungjawab penelitian Ibu Umi Chodrijah, S.Pi, M.Si.

\section{DAFTAR PUSTAKA}

Anonim, (2000). The living marine resources of the Western Central Pasific. Vol. 6. Bony fishes part 4 (Labridae to Latimeriidae), estuarine crocodiles, sea turtles, sea snakes and marine mammals). FAO Species Identifcation Guide for Fishery Purposes. ISSN 1020-6868:3721-3764 p.

Carpenter, K.E. \& V.H. Niem. (1998). FAO species identification guide for fishing purposes. The Living Marine Resources of the Western Central Pasific. Vol. 2. Cephalopods, crustaceans, holoturians and sharks. FAO, Rome: 1194-1366. 